Original Research Paper

\title{
Effect of Feed Additive Supplementation on Growth Performance, Intestinal Morphology, Intestinal Microflora and Nutrient Digestibility Study of Broiler Chicken
}

\author{
${ }^{1}$ Sunday Egba Omogo, ${ }^{2}$ Emeka Henry Oparaji and ${ }^{1}$ Franklin Uzodinma Edeji \\ ${ }^{1}$ Department of Biotechnology, Enzyme Division, Federal Institute of Industrial Research, Oshodi, Lagos State, Nigeria \\ ${ }^{2}$ Department of Biochemistry, University of Nigeria, Nsukka, Enugu State, Nigeria
}

\author{
Article history \\ Received: 17-11-2020 \\ Revised: 02-01-2021 \\ Accepted: 08-01-2021 \\ Corresponding Author: \\ Sunday Egba Omogo \\ Department of Biotechnology, \\ Enzyme Division, Federal \\ Institute of Industrial Research, \\ Oshodi, Lagos State, Nigeria \\ Email: omogoegba@yahoo.com
}

\begin{abstract}
The present study evaluated the effect of various feed additive supplementation on growth performance, intestinal morphology, intestinal microflora and nutrient digestibility study of starter broiler chicks. A day-old broiler chicks with total number of two hundred and four (204) (Ross 308) were randomly allotted to eight (8) dietary treatments with four (4) replicate pens per treatment (average of 6 birds per replicate pen). Chicks in each treatment were allowed ad libitum access to their diet and water for thirty-five (35) days. Dietary supplement for the 35 days were: Corn-soyabean meal basal diet (control); control $+0.01 \%$ antibiotics; control $+0.1 \%$ probiotics; control $+0.02 \%$ prebiotics; control $+0.06 \%$ essential oil; control $+0.6 \%$ organic acid; control $+0.1 \%$ enzyme and control + all the additives in the treatment groups (mixture). Growth performance results showed that there was significant increase $(\mathrm{p}<0.05)$ in final weight, total weight gain, average daily, weight gain, feed conversion ratio and feed efficiency of broiler of broiler chicks fed diet of antibiotics and prebiotics compared to the control group. Studies on the Ileal morphology parameters from day 1 to day 35 of broiler chicks fed with antibiotics and prebiotics additives indicated that there was significant increase $(\mathrm{p}<0.05)$ in villus height, illus width and muscle thickness of the chicks when compared with the control group. Result for the cecal morphology revealed that there was significant increase $(\mathrm{p}<0.05)$ in mucosal thickness, muscularis thickness and the ratio of mucosal thickness to muscularis thickness of chicks fed antibiotics and prebiotics compared to the control group. Studies on the microbial ileal and cecal composition showed that there was significant decrease $(\mathrm{p}<0.05)$ in ileal and cecal pathogenic bacteria; E. coli and Salmonella sp. of fed supplement of antibiotics, probiotics and prebiotics compared to the control group. There was a significant decrease $(\mathrm{p}<0.05)$ in Lactobacillus $\mathrm{sp}$. in ileal and cecal of broiler chicks with fed supplement of antibiotics, probiotics and prebiotics compared to the control group. The present study has shown the efficacy and wide utility of prebiotics especially for organic practicing poultry farming; it has also validated their usage (s) as good substitute for antibiotic and other adjourning anti-microbial growth promoter xenobiotics whose applications has been banned in poultry industries.
\end{abstract}

Keywords: Poultry, Intestinal Morphology, Intestinal Microflora, Antibiotics, Broiler Chicks

\section{Introduction}

The biggest challenge posed on commercial poultry production is solely on the accessibility of good quality feed on sustainable basis at stable prices which are affordable. Nevertheless, commercial poultry production ranks among the highest source at which animal protein can be found (Gabriel et al., 2006). The trend at which the size of the poultry industry is increasing has been faster than other animal food-producing industries. The trade 
volume of poultry products has also increased in tandemwith growth of global poultry meat and egg production (Apajalahti et al., 2004). Available data indicate that the poultry meat industry has been more proficient in terms of growth wide range in production compared with the egg industry over these years (Apajalahti et al., 2004). Feed and strains of chicksare the major component of the total cost of production of meat and egg production in the poultry industry.

Keeping every other conditions constant with normal feeding habit, broiler birds can attain a weight of $2-3 \mathrm{~kg}$ within five to six weeks. With the current advent of excluding antibiotic growth promoters in poultry production in Europe and America, the problems of controlling enteric infections caused by pathogenic bacteria without the use of antibiotics becomes challenging. The rate of mortality caused by infection is a major problem in the poultry industry (Gabriel et al., 2006). Such infections are the cause of reduced growth rates and consequent economic losses in poultry. Antibiotics are the foremost tools used to prevent or treat such infections. In animals, antibiotics serves as growth promoters which is used to accelerate the growth of healthy animals. Unfortunately, extensive use of antibiotics for veterinary purpose may eventually result in selection for the survival of resistant bacteria species or strain (Aarestrup, 1999). Genes that codes for this resistance also can be transferred to other formerly susceptible bacteria, thereby causing a threat to both animal and human health (Montagne et al., 2003). Growth promoters have been utiliized extensively in animal feeds and water all over the world especially in the poultry and pig industries (Charles and Duke, 1978). Antibiotics improve the production result of meat producing chicks. However, the use of Antibiotic Growth Promoters (AGP) is being placed under consideration as consumer continously fear that their use in feed rations of productive live stocks leads to resistance against bacteria which are pathogenic to humans (Houshmand et al., 2012). Prebiotics have advantage compared with probiotics. The known prebiotics are Fructo-Oligosaccharide products (FOS, oligofructose, inulin) (Patterson and Burkholder, 2003) FOS is one of the commercially accessible prebiotics which have been tried in poultry with much success (Lee et al., 2010). Thus, the main objective of this experiment was to study and compare the efficacy of various feed additive supplementation on these poultry parameters-growth performance, intestinal morphology, intestinal microflora and nutrient digestibility study of starting broiler chicks.

\section{Materials and Methods}

\section{Samples and Sample Area}

A total of 204 one day-old broiler chicks (Ross 308 hatchery brand) were purchased from a local hatchery at Ibadan, Oyo state, Nigeria (Agrited White Plains Limited.). They were randomly allotted to 8 dietary treatments (four (4) replicate each having average of six (6) birds per replicate) at animal house, College of medicine, University of Lagos, Lagos state, Nigeria. The birds were vaccinated against New castle and Gumboro's diseases and basic nutrient were provided for them upon arrival as described by NRC (1994).

\section{Determination of Growth Performance}

Growth performances of broiler chicks were evaluated as described by (NRC, 1994). Body weight gain, feed intake, feed conversion ratio and mortality of the broiler chicks were recorded during the 35 days experimental period.

Feed conversion:

$$
\text { feed intake } \div \text { body weight gain }
$$

Feed efficiency:

$$
\text { Average feed intake / Average weight gain } \times 100
$$

\section{Extraction of the Broiler Chicks Intestinal Contents}

Intestinal contents of the broiler chicks (ceca and ileal) were extracted as described by Oyibo et al. (2018). Birds totaling four (4) in numbers with average mean body weight-BW, were selected from each group (one per replicate). The birds were weighed and exsanguinated by cutting their jugular vein and blood samples were individually collected in $10 \mathrm{~mL}$ heparinised tubes and plain tubes and then stored on ice for blood hematology and serum chemistry analysis. After blood collection, the gastrointestinal tract was removed from the carcasses, both ceca and ileal were dissected and approximately $1 \mathrm{~g}$ each was aseptically collected into a $2 \mathrm{~mL}$ safe-lock Eppendorf tube. The cecal contents were immediately frozen at $-40^{\circ} \mathrm{C}$ for future microflora analysis.

\section{Identification and Quantification of Ileal and Cecal Microflora}

One gram of composite of cecal and ileal from each pen was diluted with $2 \mathrm{~mL}$ of $0.9 \%$ normal saline and was used to prepare a stock solution and mixed on a vortex machine. Viable counts of bacteria in the cecal and ileal samples were then conducted as described by Ezeonu et al. (2012). Briefly, a 10-fold serial dilutions $\left(10^{-1}\right.$ to $\left.10^{-10}\right)$ of the stock in a $9 \mathrm{~mL}$ of $0.9 \%$ normal saline solution was carried out and then plating $10^{-3}, 10^{-5}, 10^{-7}$ and $10^{-9}$ dilution factors of both cecal and ileal stock solutions into prepared DeMan Ragos and Sharpe (MRS) agar plates, MacConkey agar plates and shigella agar plates (Difco Laboratories, Becton, Dickinson and 
Company, Sparks, MD) to isolate the Lactobacillus, Escherichia coli and Salmonella, respectively. The inoculated plates were incubated at respective conditions as described in the atlas of bacteriology:

$$
\begin{aligned}
& \text { Bacteria count }(\mathrm{CFU} / \mathrm{ml}) \\
& =\text { colony count } / \text { volume pippeted } \times \text { dilution factor }
\end{aligned}
$$

\section{Measurement of Ileal and Cecal Morphology}

These were carried out as described by Apajalahti et al. (2004). About $1 \mathrm{~cm}$ of tissue samples from ileal and caecal were collected from the distal part of each bird. Both ileum and caecum collected from the slaughtered birds were then fixed in $10 \%$ buffered formalin saline (pH 7.4). Tissues were dehydrated by immersing through a series of alcohols with increasing concentrations of 70-99.9\%, infiltrated with xylene and embedded in paraffin. Casting of blocks was carried out in L-molds (two L-shaped pieces) which facilitated the manipulation of size as per the requirement. The rotary type microtome was used for cutting the paraffin sections. The blocks were properly trimmed and the sections of $5 \mathrm{~mm}$ thickness were cut. Continuous ribbons (6-7 inches long) of the material were cut and laid on the surface of constant temperature water bath (around $55^{\circ} \mathrm{C}$ ). The sections were separated with a heated scalpel after they spread completely. The cut sections were mounted on the clean glass slides using Mayer's egg albumin as the section adhesive. The mounted slides were dried in paraffin oven at $60^{\circ} \mathrm{C}$ for one hour. The tissue sections were stained by the Harris haematoxylin and eosin staining method.

The paraffin sections were deparaffinised with the xylene before hydration through graded alcohol to distilled water. This was followed by the dehydration in ascending grades of alcohol. The clearing was performed in the xylene and a drop of Distrene Plasticiser Xylene (DPX) mount was placed on a cover slip and the section on the slide pressed on it. The slide was inverted and the cover slip was pressed with a rod to remove the air bubbles, if any trapped. The values were measured with an oculometer at a magnification of 10x under a light microscope fitted with the stage micrometer. Villus height (tip to the bottom), villus width at its base and external muscle layer thickness (muscularis mucosa + submucosa + muscle) were examined $(\times 100)$ under a light microscope for the ileal morphology (Olympus Co. Ltd., BX 50, F-3, Tokyo, Japan) with a camera (Focus Light, Version 2.88).

Also, Mucosal thickness and Muscularis thickness for the caecal were examined $(\times 100)$ under a light microscope with a camera. Four (4) microscopic fields per bird were measured and the average value was expressed as the morphological value for each bird.

\section{Nutrient Digestibility Studies}

\section{Collection of Ileal Digesta}

This was carried out as described by Apajalahti et al. (2004). Broiler chicks were slaughtered two (2) after feeding which ended their twenty-four hours of fasting on day thirty-three (33) of the experimental periods. The body cavity was opened, the ileum removed and digesta collected from the ileum. Ileal digesta of birds within a cage were pooled using $2 \mathrm{~mL} \mathrm{9 \%} \mathrm{normal} \mathrm{saline} \mathrm{to} \mathrm{provide} \mathrm{adequate}$ material for chemical analysis. The digesta were frozen immediately after collection at $-20^{\circ} \mathrm{C}$ to preserve it.

\section{Collection of Fecal/Excreta Sample}

This was carried out as described by Kadim and Moughan (1997). After one hour feeding period of the broiler chicks on day forty-seven (47) of the experimental periods, excreta were collected for $13 \mathrm{~h}$ on a spread metallic sheet placed underneath each cage, transferred to a plastic container and frozen $\left(-20^{\circ} \mathrm{C}\right)$. The excreta and digesta samples were subsequently freeze dried, finely ground and stored at $-20^{\circ} \mathrm{C}$ pending chemical analysis.

The crude protein and crude fibre concentration of the diets, the ileal digesta and excreta samples were determined as described by (Association of Official Analytical Chemists, 1990). Dry Matter (DM) (934.01) content was determined according to (Association of Official Analytical Chemists, 1990) procedures and chromic oxide $\left(\mathrm{Cr}_{2} \mathrm{O}_{3}\right)$ determination was done using atomic absorption spectrophotometry, following the method of (Fenton and Fenton, 1979).

Nutrient digestibility was calculated using the following equations (Kadim et al., 2002):

- $\quad$ AA output = AA concentration in digesta or excreta $\mathrm{x}$ (Diet $\mathrm{Cr}_{2} \mathrm{O}_{3}$ concentration $/ \mathrm{Cr}_{2} \mathrm{O}_{3}$ concentration in digesta or excreta)

- $\quad$ Nutrient AA digestibility $($ AID $)=($ AA concentration in feed - AA output (in ileum or excreta))/AA concentration in feed

Table 1: Feed composition of diet from 0-35 days

\begin{tabular}{lc}
\hline Ingredients $(\%)$ & Starter diet $(0-35 \mathrm{~d})(\mathrm{kg})$ \\
\hline Corn & 57.90 \\
Soya & 34.90 \\
Soya oil & 3.00 \\
Limestone & 1.00 \\
Dicalcium phosphate & 2.00 \\
NaCl & 0.30 \\
Methionine & 0.30 \\
Lysine & 0.20 \\
Premix* & 0.40 \\
Total & 100.00 \\
Proximate Analysis & \\
Crude protein & 18.87 \\
Fat & 4.00 \\
Crude fibre & 3.00 \\
Ash & 9.24 \\
Moisture & 8.85 \\
Metabolizable energy-ME (Kcal/kg) & 2653.00 \\
\hline
\end{tabular}




\section{Statistical Analysis}

The calculated data were analyzed using the statistical software package SAS. The results were subjected to oneway Analysis of Variance (ANOVA) followed by Duncan's multiple-range test. Statistical significance was established at $\mathrm{p}<0.05$.

Table 1 shows the composition of the supplement additives given to the broiler chicks from day 0-35.

\section{Results}

Table 2 shows the effect of different feed additive supplementation on growth performance of broilers (0-35 days).

The results obtained showed that there was significant increase $(p<0.05)$ in final weight of broiler chicks fed diet of organic acid compared to the control group. Also, there was no significant change ( $p>0.05)$ in final weight of broiler chicks fed diet of probiotics, organic acid, essential oil, enzyme and mixture respectively compared to the control group.

Table 3 shows the effect of different additive supplementation on ileal morphology of broiler chicks.

There was a significant increase $(\mathrm{P}<0.05)$ in villus height and villus width of chicks fed antibiotics and prebiotics compared to the control group. There was no significant change ( $>0.05)$ in villus height and villus width of chicks fed probiotics, essential oil, organic acid, enzyme and mixture compared to the control group. There was a significant increase $(\mathrm{p}<0.05)$ in muscle thickness of chicks fed antibiotics and prebiotics compared to the control group. There was no significant difference ( $>0.05)$ in muscle thickness of chicks fed probiotics, essential oil, organic acid, enzyme and mixture compared to the control group.

Table 4 shows the effect of different feed supplementation on cecal morphology of broiler.

Table 2: Effect of different feed additive supplementation on growth performance of broilers (0-35days)

\begin{tabular}{llllllll}
\hline & FNLWT $(\mathrm{g})$ & TOTWTG $(\mathrm{g})$ & ADWTG $(\mathrm{g} /$ day $)$ & TOTFINT $(\mathrm{g})$ & ADFI $(\mathrm{g} /$ day $)$ & FCR & FE $(\%)$ \\
\hline Control & $1440.00 \pm 23.92$ & $1329.00 \pm 25.93$ & $39.25 \pm 0.74$ & $2115.00 \pm 87.890$ & $60.43 \pm 2.51$ & $1.54 \pm 0.09$ & $0.65 \pm 0.03$ \\
Antibiotics & $1505.00 \pm 48.3^{*}$ & $1441.00 \pm 47.18^{*}$ & $41.17 \pm 1.35^{*}$ & $1970.00 \pm 67.670$ & $56.29 \pm 1.93$ & $1.67 \pm 0.02^{*}$ & $0.73 \pm 0.01^{*}$ \\
Probiotics & $1323.00 \pm 47.10$ & $1349.00 \pm 47.57$ & $35.70 \pm 1.36$ & $1996.00 \pm 66.810$ & $57.04 \pm 1.91$ & $1.60 \pm 0.01$ & $0.63 \pm 0.00$ \\
Prebiotics & $1543.00 \pm 16.36$ & $1574.00 \pm 15.37^{*}$ & $56.40 \pm 0.44^{*}$ & $2025.00 \pm 78.390$ & $57.85 \pm 2.24$ & $1.79 \pm 0.07^{*}$ & $0.77 \pm 0.03^{*}$ \\
Essential oil & $1367.00 \pm 45.76$ & $1306.00 \pm 45.45$ & $37.34 \pm 1.30$ & $1899.00 \pm 135.50$ & $54.27 \pm 3.87$ & $1.46 \pm 0.09$ & $0.70 \pm 0.04$ \\
Organic Acid & $1371.00 \pm 84.68$ & $1320.00 \pm 84.89$ & $34.14 \pm 2.43$ & $2077.00 \pm 160.34$ & $59.36 \pm 4.58$ & $1.52 \pm 0.02$ & $0.60 \pm 0.01$ \\
Enzyme & $1360.00 \pm 42.19$ & $1295.00 \pm 41.44$ & $36.99 \pm 1.18$ & $1896.00 \pm 72.130$ & $54.18 \pm 2.06$ & $1.47 \pm 0.10$ & $0.69 \pm 0.05$ \\
Mixture & $1380.00 \pm 47.69$ & $1309.00 \pm 46.09$ & $37.40 \pm 1.32$ & $1918.00 \pm 80.730$ & $54.79 \pm 2.31$ & $1.47 \pm 0.05$ & $0.68 \pm 0.02$ \\
\hline
\end{tabular}

Key: Final Weight (FNLWT), Total Weight Gain (TOTWTGN), Average Daily Weight Gain (ADWTG), Total Feed Intake (TOTFINT), Average Daily Feed Intake (ADFI), Feed Conversion Ratio (FCR), Feed Efficiency (FE) Result were expressed as mean \pm SD; $n=4$

Different superscripts within the same column signifies statistical difference at $\mathrm{p}<0.05$

Table 3: Effect of different feed additive supplementation on ileal morphology of broiler (0-35days)

\begin{tabular}{lllll}
\hline S/N & Treatment groups & Villi height $(\mu \mathrm{m})$ & Villi width $(\mu \mathrm{m})$ & Muscularis thickness $(\mu \mathrm{m})$ \\
\hline 1. & Control & $687.50 \pm 0.05$ & $50.00 \pm 2.00$ & $275.00 \pm 1.00$ \\
2. & Antibiotics & $762.00 \pm 1.00^{*}$ & $65.00 \pm 2.00^{*}$ & $295.00 \pm 2.00^{*}$ \\
3. & Probiotics & $690.50 \pm 0.10$ & $50.00 \pm 1.00$ & $276.00 \pm 1.60$ \\
4. & Prebiotics & $750.50 \pm 0.10^{*}$ & $60.50 \pm 0.10^{*}$ & $287.50 \pm 0.10^{*}$ \\
5. & Essential oil & $680.50 \pm 0.10$ & $47.55 \pm 0.05$ & $275.00 \pm 1.00$ \\
6. & Organic acid & $675.00 \pm 1.00$ & $47.50 \pm 0.10$ & $277.00 \pm 1.00$ \\
7. & Enzyme & $683.00 \pm 1.00$ & $45.00 \pm 1.00$ & $270.50 \pm 0.10$ \\
8. & Mixture & $679.50+0.10$ & $47.50 \pm 0.10$ & $272.50 \pm 0.10$ \\
\hline
\end{tabular}

Results represented as mean \pm S.E.M; *statistically significant at $\mathrm{p}<0.05, \mathrm{n}=4$

Table 4: Effect of different feed additive supplementation on cecal morphology of broiler (0-35days)

\begin{tabular}{|c|c|c|c|c|}
\hline $\mathrm{S} / \mathrm{N}$ & Treatment groups & Mucosal thickness $(\mu \mathrm{m})$ & Muscularis thickness $(\mu \mathrm{m})$ & $\begin{array}{l}\text { Mucosal thickness }(\mu \mathrm{m}) \\
\text { Muscularis thickness }(\mu \mathrm{m})\end{array}$ \\
\hline 1. & Control & $225.50 \pm 0.50$ & $250.50 \pm 0.50$ & $0.90 \pm 1.00$ \\
\hline 2. & Antibiotics & $243.00 \pm 0.50 *$ & $274.80 \pm 0.20 *$ & $0.65 \pm 1.25^{*}$ \\
\hline 3. & Probiotics & $220.00 \pm 0.50$ & $257.60 \pm 0.05$ & $0.74 \pm 1.00 *$ \\
\hline 4. & Prebiotics & $240.00 \pm 0.50 *$ & $270.80 \pm 0.75^{*}$ & $0.71 \pm 0.15^{*}$ \\
\hline 5. & Essential oil & $222.70 \pm 0.15$ & $250.80 \pm 0.80$ & $0.85 \pm 0.20$ \\
\hline 6. & Organic acid & $226.70 \pm 0.20$ & $256.70 \pm 0.70^{*}$ & $0.71 \pm 0.12 *$ \\
\hline 7. & Enzyme & $223.00 \pm 0.50$ & $249.80 \pm 0.20 *$ & $0.80 \pm 0.24 *$ \\
\hline 8. & Mixture & $220.50 \pm 1.00$ & $248.50 \pm 0.10^{*}$ & $1.00 \pm 0.50 *$ \\
\hline
\end{tabular}

Results represented as mean \pm S.E.M; *statistically significant at $\mathrm{p}<0.05, \mathrm{n}=4$ 
There was significant increase $(\mathrm{P}<0.05)$ in mucosal thickness, muscularis thickness and the ratio of mucosal thickness to muscularis thickness of chicks fed antibiotics and prebiotics compared to the control group. There was no significant change ( $>0.05)$ in mucosal thickness, muscularis thickness and the ratio of mucosal thickness to muscularis thickness of chicks fed probiotics, essential oil, organic acid, enzyme and mixture compared to the control group.

Table 5 shows the effect of different feed additive supplementation on apparent protein digestibility of broiler.

The antibiotic treatment group followed by the prebiotic treatment group had the highest ileal protein content compared to all the treatment groups while mixture treatment group had the least ileal protein content compared to the control and other treatment groups. Also, the antibiotic treatment group followed by the prebiotic treatment group had the highest cecal protein content compared to all the treatment groups while mixture had the least cecal content compared to the control group and other treatment groups.

Figure 1 shows the pictograph of ileum of broiler chicken at day 35 .

The pictograph of the ileum showed the density and size of villi and microvilli of small intestine which is directly related to their absorption capacity. Figure 1 showed that the height of the villi of broiler chicks treated with prebiotics is longer than others in the other treatment groups as compared to the control group.

Figure 2 shows the pictograph of cecum of broiler chicken at day 35 .

The pictograph of the cecum showed the density and size of villi and microvilli of small intestine which is directly related to their absorption capacity. Figure 2 showed that the height of the villi of broiler chicks treated with probiotics is longer than others in the other treatment groups as compared to the control group.

Figure 3 shows the effects of different feed additive supplementation on ilieal microflora $(\mathrm{CFU} / \mathrm{ml})$ content of broilers (0-35 days).

There was significant increase $(\mathrm{p}<0.05)$ in ileal pathogen; $E$. coli of fed diet of essential oil, organic acid, enzyme and mixture compared to the control group. However, there was significant decrease $(p<0.05)$ in ileal pathogen; E. coli of fed diet of antibiotics, probiotics and prebiotics compared to the control group.

Figure 4 shows the effects of different feed additive supplementation on cecal microflora $(\mathrm{CFU} / \mathrm{ml})$ content of broilers (0-35 days).

Table 5: Effect of different feed additive supplementation on apparent protein digestibility of broiler (0-35 days). Chromic reading (diet reading $=1.000 \mathrm{mg} / \mathrm{L})$

\begin{tabular}{lllllllll}
\hline & Control & Antibiotics & Probiotics & Prebiotics & Essential oil & Organic acid & Enzyme & Mixture \\
\hline Ileal protein & $0.823 \pm 0.05$ & $0.867 \pm 0.10$ & $0.827 \pm 0.06$ & $0.856 \pm 0.10$ & $0.827 \pm 0.05$ & $0.824 \pm 0.06$ & $0.819 \pm 0.06$ & $0.815 \pm 0.05$ \\
Feacal protein & $0.849 \pm 0.15$ & $0.878 \pm 0.11$ & $0.854 \pm 0.04$ & $0.864 \pm 0.07$ & $0.826 \pm 0.04$ & $0.845 \pm 0.04$ & $0.844 \pm 0.10$ & $0.840 \pm 0.09$ \\
\hline
\end{tabular}

Results represented as mean \pm S.E.M; * statistically significant at $\mathrm{p}<0.05, \mathrm{n}=4$

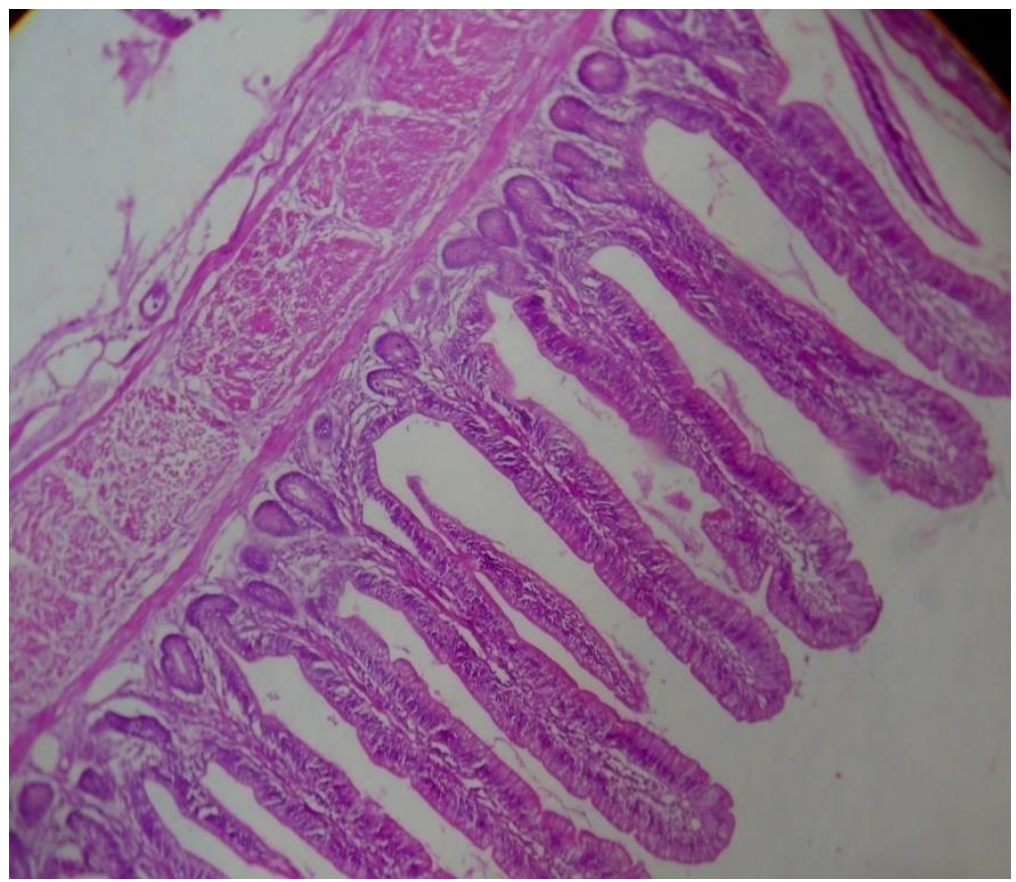

Fig. 1: Pictograph of ileum of broiler chicken at day 35 


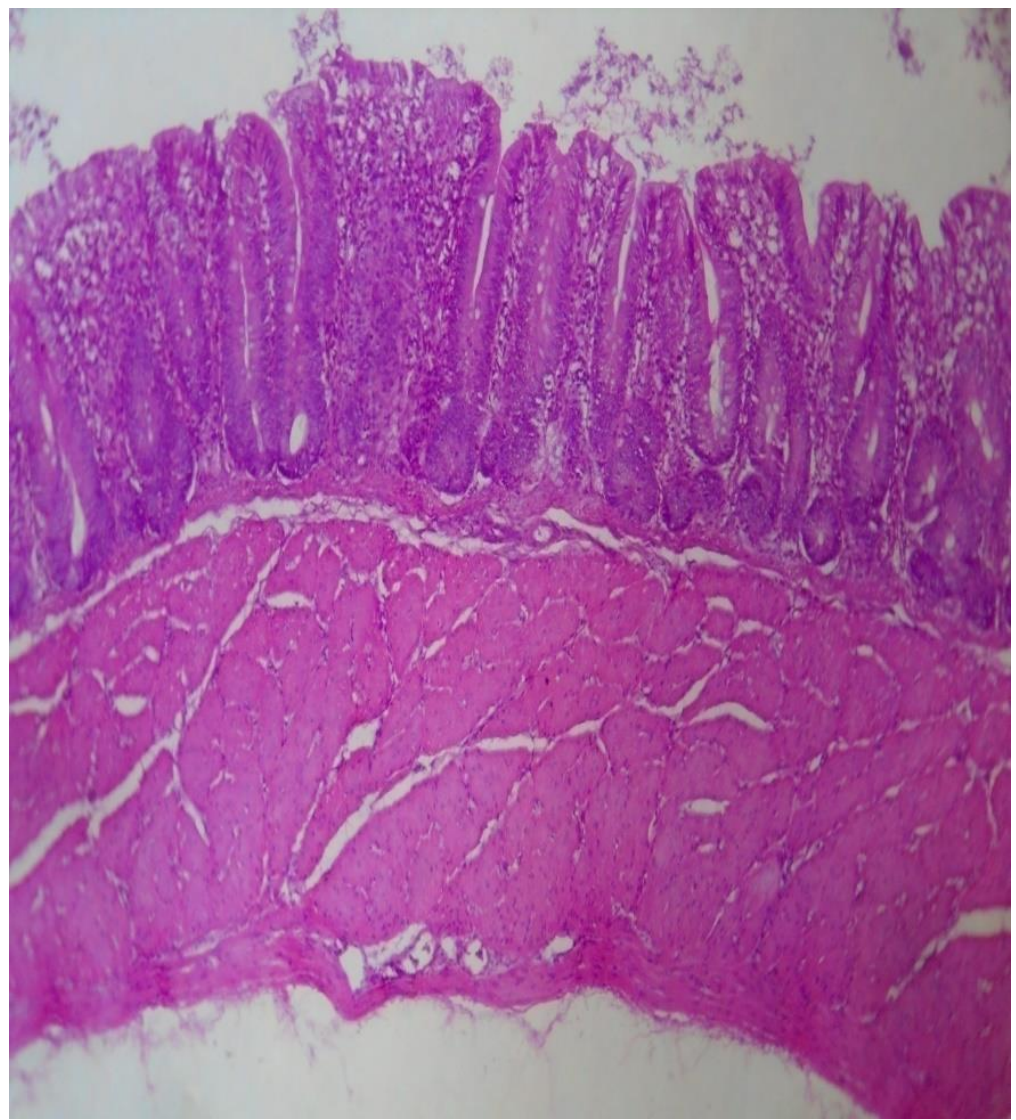

Fig. 2: Pictograph of cecum of broiler chicken at day 35

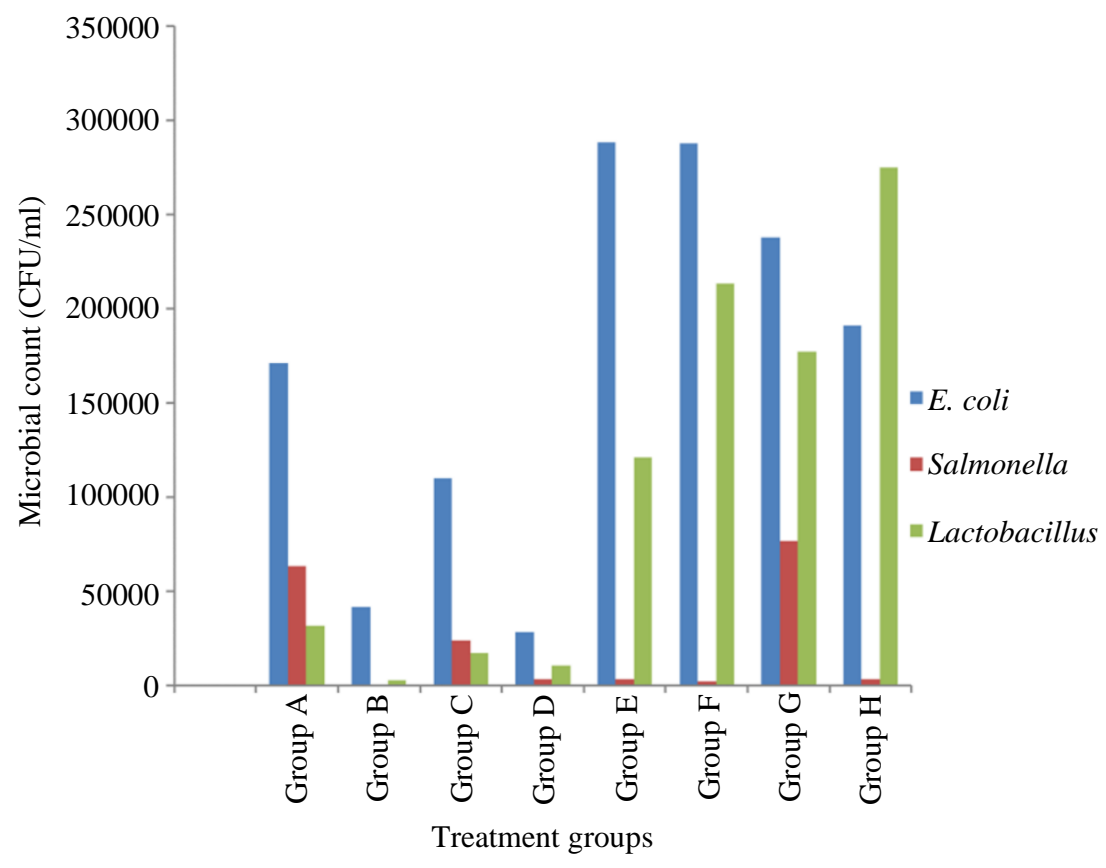

Fig. 3: Effects of different feed additive supplementation on ileal microflora content of broilers (0-35 days); KEY: Group A: Control Group C: Probiotics Group E: Essential oil Group G: Enzyme; Group B: Antibiotics Group D: Prebiotics Group F: Organic acid Group H: Mixture 


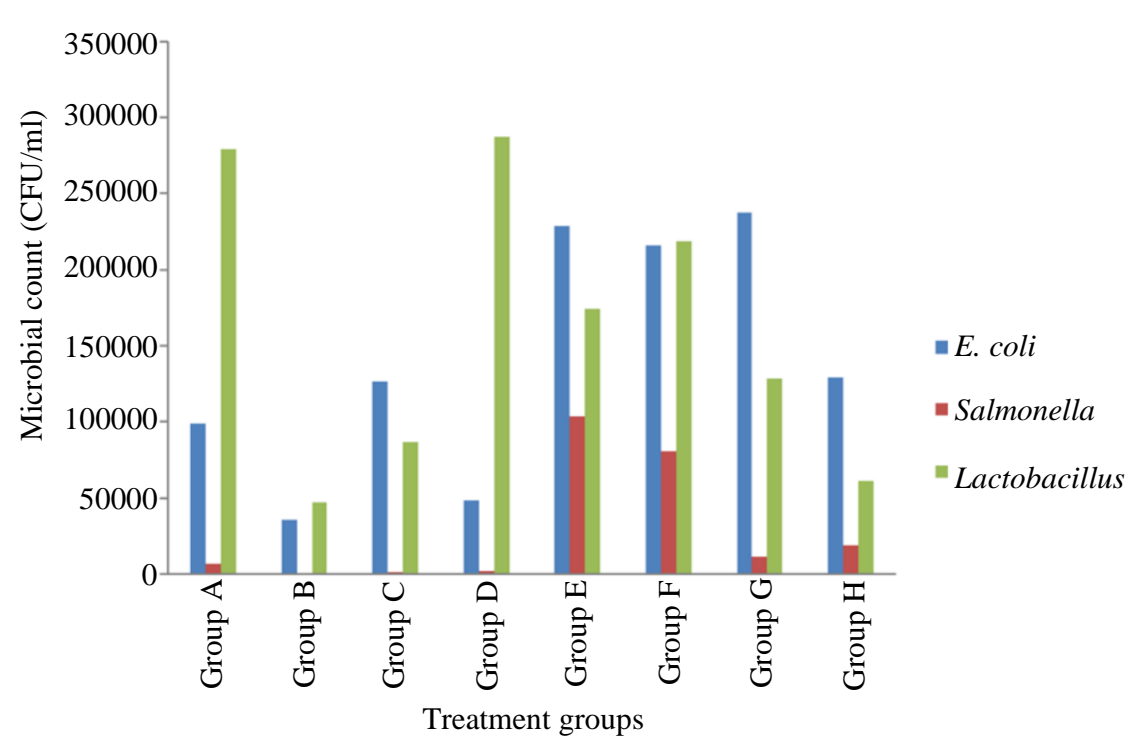

Fig. 4: Effect of different feed additive supplementation on cecal microflora content of broilers (0-35 days); Key: Group A: Control Group C: Probiotics Group E: Essential oil Group G: Enzyme; Group B: Antibiotics Group D: Prebiotics Group F: Organic acid Group H: Mixture

There was significant increase $(\mathrm{p}<0.05)$ in cecal $E$. coli of chicks fed diet of essential oil, probiotics, organic acid, enzyme and mixture compared to the control group. Also, there was significant decrease $(\mathrm{P}<0.05)$ in cecal $E$. coli of chicks fed diet of antibiotics and prebiotics compared to the control group. There was significant increase $(p<0.05)$ in cecal Salmonella of chicks fed diet of essential oil, organic acid, enzyme and mixture compared to the control group.

\section{Discussion}

This study was conducted to evaluate and compare the effect of various feed additives on the growth performance, intestinal morphology, intestinal microbiota and nutrient digestibility studies of starting broiler chicks. The additives tested included probiotics, essential oil, antibiotics, enzymes, organic acid, prebiotics and mixture of all the treatment groups.

Results obtained from Table 2 which showed the impact of probiotics, antibiotics, essential oil, enzymes, organic acid, prebiotics and mixture of all the treatment groups. The results obtained showed that there was significant increase $(p<0.05)$ in final weight of broiler chicks fed diet of antibiotics and prebiotics compared to the control group. Also, the Table 2 showed that there was significant decrease $(\mathrm{p}<0.05)$ in final weight of broiler chicks fed diet of organic acid compared to the control group. Also, Table 2 went further to reveal that there was no significant change $(p>0.05)$ in final weight of broiler chicks fed diet of probiotics, organic acid, essential oil, enzyme and mixture respectively compared to the control group. The increased body weight gain in chicks fed with prebiotics may be due to improvement in digestibility and availability of many nutrients such as proteins, fats and carbohydrates, as well as, some mineral elements and vitamins (Burkholder et al., 2005). It was noteworthy that many of the beneficial bacteria enhanced the effect of endogenous enzymes that are produced naturally within the gastrointestinal tract (Naji et al., 2009).

There was no significant difference $(p>0.05)$ in total feed intake of broiler chicks fed with additive supplement of all the treatment groups compared to the control group during the different phases of experiment.

There was a significant increase $(\mathrm{p}<0.05)$ in the total weight gain of broiler chick fed diet of antibiotics and prebiotics compared to the control group. However, there was no significant change ( $>0.05)$ in total weight gain of broiler chicks fed diet of probiotics, organic acid, essential oil, organic acid, enzyme and mixture compared to the control group. There was significant increase $(p<0.05)$ in average daily weight gain of broiler chicks fed diet of antibiotics and prebiotics compared to the control group but there was no significant difference $(p>0.05)$ in the average daily weight gain of broiler chicks fed diet of probiotics, essential oil, organic acid, enzyme and mixture respectively compared to the control group.

FCR was affected by feed additives; However, during the treatment period (day 1-35), the birds receiving the diet containing the prebiotic and antibiotic respectively had a significantly better FCR than the other groups. Due to this improvement, overall (d 1-35) FCR was also better for the prebiotic and antibiotic treatment compared to the other treatments. Briefly, the performance data indicated that among the different feed additives (antibiotics, enzymes, essential oil, mixture, organic acids, probiotic and prebiotic), a significant growth promoting effect was 
observed only for the antibiotics and prebiotic while other treatment groups (enzymes, essential oil, mixture, organic acids and probiotic) had no significant difference in FCR with respect to the control group. Consequently, the dietary addition of both antibiotics and prebiotic had significant effects on performance traits.

There was a significant increase $(p<0.05)$ in feed efficiency of broiler chicks fed diet of antibiotics and prebiotics compared to the control group. Donoghue (2003), reported that the risk concerning residues of antibiotics in tissues and products that can produce allergic or toxic reactions in consumers is known to be negligible because only antibiotics that are not absorbed in the digestive tract are authorized as growth promoters. However, the wider use of antibiotics feed additives in the long run can contribute to the development of resistant bacteria to drugs used to treat infections. These microbials with resistant genes poses a potential risk for humans if they are transferred to persons. Cromwell (2002) reported that antibiotics have played a major role in the growth and development of the swine industry for more than 50 years. Their efficiency in increasing growth rate, improving feed utilization and reducing mortality from clinical diseases is well documented which is in agreement with our results. It has been suggested that the continuous use of antibiotics may contribute to a reservoir of drugresistant bacteria which may be capable of transferring their resistance to pathogenic bacteria in both animals and humans (van der Fels-Kerx et al., 2011). Continious in-feed antibiotics do not improve overall animals health or welfare. When growth promoters in poultry are withdrawn, there are usually minimal (or no) detrimental effects when measured in large studies. Beneficial effects of prebiotics on broiler performance have been shown by $\mathrm{Xu}$ et al. (2003). They reported that birds fed diets containing 0.2 and $0.4 \%$ of a prebiotic, had a better performance than the control. Xu et al. (2003) pointed out that prebiotics are able to increase digestive enzyme (intestinal protease and amylase) activity, which affect energy and protein utilization (Samarasinghe et al., 2003; Yang et al., 2009). It is possible that prebiotics, by improving the microbial ecology of the intestine, reduce passage rate of the digesta and improve the digestibility of amino acids (Biggs and Parsons, 2007). Changes in mucosal architecture and increases in villi height have been reported to be due to the supplementation of prebiotics (Yang et al., 2009). Therefore, the improved FCR in the birds fed the prebiotic supplemented diets could be related to the above mentioned effects. The dietary addition of the probiotic in the current study did not show any positive effect on performance. Similarly, (Willis and Reid, 2008) reported that the dietary inclusion of probiotics (minimum presence of $1.04 \times 108 \mathrm{CFU} / \mathrm{g}$ ) had no significant effect on broiler growth performance. In the current study, broiler performance was not affected by organic acids supplementation. These results are in agreement with the results of (Hernandez et al., 2006), who did not find any positive effects of organic acids on performance. They concluded that the lack of significant effects on performance could be related to ideal rearing condition of their experiment, because growth promoting effects of antimicrobial additives will become apparent under suboptimal conditions, for instance poor hygiene condition or the feeding of low digestible diets.

The buffering capacity of the diet, presence of other antimicrobial compounds, acid type and concentration composition of diet and environment of the experiment could be considered as responsible factors for inconsistency in results (Dibner and Buttin, 2002). Therefore, attention should be paid to these factors, for example, in a recent study, (Isabel and Santos, 2009) concluded that the dietary addition of organic acids salts (calcium propionate and calcium formate) had no effect on broilers body weight and body weight gain, while birds fed a diet containing organic acids had a poorer FCR compared to the control birds. Diet palatability and therefore bird appetite can be influenced by organic acids (Cave, 1982).

Generally, results reported in the literature on the beneficial effects of probiotics, prebiotics and organic acids on broiler growth performance are inconsistent. Numerous factors such as the environment, management, nutrition, additive type, dosage and bird characteristics (age, species, stage of production) can affect broiler responses to probiotics (Yang et al., 2009), thereby accounted for the contrasting results. Farm rearing condition is a major factor contributing to variable results. Angel et al. (2005) reported that under favourable rearing condition, without any disease or stress, dietary supplementation with probiotics had no beneficial effects on broiler growth performance. In another study, (Timmerman et al., 2006) concluded that the positive effects of probiotics on high performance broilers would be lower than in low performing birds.

The density and size of villi and microvilli of small intestine are directly related to the absorption capacity of the birds. Significant effects of dietary protein and amino acids on bird performance are well documented (NRC, 1994; Torres-Rodriguez et al., 2005). Ileal morphology parameters day 1 to 35 of broiler chicks fed various feed additives are shown on Table 3 above. Ileal morphology parameters day 1 to 35 of broiler chicks fed various feed additives are shown on Table 3. Birds fed the diets containing the antibiotics followed by prebiotic had the longest duodenum villi compared to the other treatment groups. There was a significant increase $(p<0.05)$ in villus height and villus width of chicks fed antibiotics and prebiotics compared to the control group. There was no significant change $(\mathrm{p}>0.05)$ in villus height and villus width of chicks fed probiotics, essential oil, organic acid, enzyme and mixture compared to the control group. There was a significant increase $(\mathrm{p}<0.05)$ in muscle thickness of chicks fed antibiotics and prebiotics compared to the control group. There was no significant difference $(\mathrm{p}>0.05)$ in muscle thickness of 
chicks fed probiotics, essential oil, organic acid, enzyme and mixture compared to the control group.

Changes in villus height due to the supplementation with prebiotics have been reported previously. Baurhoo et al. (2007) found that birds fed diet containing a prebiotic had longer villi than those fed the control diet. This correlates with the result of the current study as seen in table three. Also, in another study conducted by Xu et al. (2003), dietary addition of a prebiotics (FOS) significantly increased villus height. They suggested that these changes may be related to the ability of FOS to create a more favourable intestinal microbial environment and are not a direct effect of FOS on the intestinal tissue. This is also similar with the results of the current study. Nonsignificant effects of organic acids on villus height have also been reported by Houshmand et al. (2012) which is in agreement with our results. They indicated that the addition of a blend of organic acids did not affect villus height or crypt depth at 7, 14, 21 and $42 \mathrm{~d}$ of age. Some information on the gut health could be obtained by studying the structure of the intestinal mucosa (Xu et al., 2003). Villus condition is a common criteria measurement for investigation of the effects of nutrition on gut physiology. However, in many cases significant correlations were not observed between performance and villus height or crypt depth (Houshmand et al., 2012). Longer villus could be considered as an indicator of an active functioning of intestinal villi. Increased villi height provides more surface area for nutrients absorption (Houshmand et al., 2012).

Table 4 shows the result for the cecal morphology of broiler chickens day 1 to 35 fed various feed additives. There was significant increase $(p<0.05)$ in mucosal thickness, muscularis thickness and the ratio of mucosal thickness to muscularis thickness of chicks fed antibiotics and prebiotics compared to the control group. There was no significant change $(p>0.05)$ in mucosal thickness, muscularis thickness and the ratio of mucosal thickness to muscularis thickness of chicks fed probiotics, essential oil, organic acid, enzyme and mixture compared to the control group.

The intestinal tracts of newly hatched chickens are basically sterile i.e., containing no microorganism. Through feeding, microbes gradually colonize the GastroIntestine Trait (GIT) forming a stable microbial consortium over time. Studies have shown that it takes 2-4 weeks for a stable microbial consortium to form in the GIT of chickens (Lee et al., 2010; Amit-Romach et al., 2004). During this period of microbial colonization of the chicken GIT, the chicks are exposed to the risk of being colonized by pathogenic organism at a period in their life cycle, when their immunity is low. Through natural selection either beneficial or pathogenic microorganisms are established in the GIT at maturity. When harmful microbes are established they could cause localized or systemic infections, intestinal putrefaction and toxic production (Jeurissen et al., 2002; Yegani and Korver, 2008). Examples of pathogenic organism commonly associated with poultry diseases causing economic losses are the protozoa Eimeria causing

coccidiosis (Willis et al., 2008; 2009a; 2009b; 2010) and the following bacteria Salmonella, E. coli, Streptococcus, Clostridium perfringes etc. Microbial infections have resulted in chicks weight loss, death and poor meat quality. In the current study, figure three shows the result for the ileal microflora of the broiler chicks. There was significant increase $(\mathrm{p}<0.05)$ in ileal pathogen; $E$. coli of fed diet of essential oil, organic acid, enzyme and mixture compared to the control goup. However, there was significant decrease $(\mathrm{p}<0.05)$ in ileal pathogen; $E$. coli of fed diet of antibiotics, probiotics and prebiotics compared to the control group. This result depicts that that the birds fed with antibiotics or prebiotics are resistant to the pathogenicity of $E$. coli whereas the birds fed with essential oil, organic acid, enzyme and mixture are more prone to the pathogenicity of E. coli.

There was a significant increase $(\mathrm{p}<0.05)$ in another ileal pathogen; Salmonella of fed diet enzyme compared to the control group. Also, there was significant decrease $(p<0.05)$ in another ileal pathogen; Salmonella of fed diet of probiotics, prebiotics, organic acid, essential oil and mixture compared to the control group. However, there was no presence of Salmonella antibiotic fed diet. This result depicts that that the birds fed with antibiotics or prebiotics or probiotics are resistant to the pathogenicity of Salmonella whereas the birds fed with essential oil, organic acid, enzyme and mixture are more prone to the pathogenicity of Salmonella sp. There was significant increase $(p<0.05)$ in microflora of beneficial microorganism; Lactobacillus sp. of fed diet of essential oil, organic acid enzyme and mixture compared to the control group. Also, there was significant decrease $(p<0.05)$ in Lactobacillus of fed diet of antibiotics, probiotics and prebiotics compared to the control group. Figure 4r shows the result for the cecal microflora of broiler chickens. There was significant increase $(\mathrm{p}<0.05)$ in cecal $E$. coli of chicks fed diet of essential oil, probiotics, organic acid, enzyme and mixture compared to the control group. Also, there was significant decrease $(\mathrm{p}<0.05)$ in cecal $E$. coli of chicks fed diet of antibiotics and prebiotics compared to the control group. There was significant increase $(\mathrm{p}<0.05)$ in cecal Salmonella of chicks fed diet of essential oil, organic acid, enzyme and mixture compared to the control group. However, there was no presence of Salmonella in chicks fed diet of antibiotics. There was significant increase $(\mathrm{p}<0.05)$ in Lactobacillus sp. of chicks fed diet of prebiotics compared to the control group. Also, there was significant decrease $(\mathrm{p}<0.05)$ in Lactobacillus $\mathrm{sp}$. of chicks fed diet of antibiotics, probiotics, essential oil, organic acid enzyme and mixture compared to the control group.

On the other hand, beneficial microbes, which are now developed as prebiotics and probiotics suppress and evade pathogenic microbes through various mechanism such as competition for food and attachment sites at the GIT (competitive exclusion), production of acidic metabolites 
to make the GIT unsuitable for pathogenic organisms and the stimulation of immunity (immunoglobulin proteins) to fight invading pathogenic microbes. Other documented functions of GIT colonized by beneficial microbes include production of nutrient and vitamins, reduction in meat contamination, enhancement of animal performance, prevention of inflammatory reactions (Jeurissen et al., 2002; Patterson and Burkholder, 2003; Yegani and Korver, 2008). Apajalahti et al. (2004) reported that there are about 107-1011 bacteria CFU/g of gut digest and through molecular studies indentified 640 species belonging to 140 genera. The microbial ecology of chicken GIT is quite unique. At maturity, the chicken GIT is quite diverse consisting mostly of bacteria and to a lesser extent protozoa and fungi (Gabriel et al., 2006). The diversity/composition of the microbial flora of chicken GIT depends on several factors including diet composition, age of the chicken, breed, geographic location and the specific section of the GIT such as small intestine, ileum, cecum (Apajalahti et al., 2001; 2002; 2004). It has been variously reported that each region of the chicken intestine develop its own unique microflora (Yegani and Korver, 2008; Amit-Romach et al., 2004; Gong et al., 2002a; 2002b). Though, reported that generally the population of the GIT tends to increase from proximal to the distal of the GIT. Apajalahti et al. (2002) reported that the population of the bacteria in the ileum was 108 and $109 \mathrm{CFU} / \mathrm{g}$ of the digesta at 1 and 3 days old respectively, whereas at the cecum they were 1010 and $1011 \mathrm{cfu} / \mathrm{g}$, respectively. Another study carried out by Apajalahti et al. (2004) show that the basal nutrients of poultry diet affect the diversity of bacteria in the GIT with feeds containing corn/sorghum, barley, oats and rye preferentially stimulating the population of Enterococcus sp., Lactobacillus sp., E. coli, Lactococus sp. and Streptococcus $\mathrm{sp}$. respectively.

Inspite of considerable progress in chemical composition methods, there is no any doubt that availability and digestibility of nutrients play the major role in poultry feedstuffs (Papadopoulos, 1998). Birds with normal feed intake patterns have a characteristic gastrointestinal flow dynamic and the indicators present in the diets assume a similar condition in order to obtain an accurate estimate. However, it is known that birds feature has different feed intake pattern when submitted the different diets. Gao et al. (2008) justified that reduced feed intake can affect the dynamic equilibrium and the accuracy of the estimate of nutrient digestibility coefficient which is in agreement with our results. In the same study, (Batal and Parsons, 2002) further established that feed composition directly interferes with digestibility. In that study, the researchers compared a purified diet (dextrosecasein) to a practical diet (corn soybean meal) and observed increased digestibility of protein fraction components for the practical diet in two to 21 day old of broiler chicks which is in agreement with our results. This observation could be as a result high quantity of pathogenic microflora in the gut of the broiler chicks fed diet of supplemented feed additives which made them not to have a better feed conversion ratio. Parsons (1984) found that hindgut fermentable carbohydrates caused an increase in amino acid secretion in intact rather than in caecectomised birds, the amount of energy-yielding carbohydrates reaching the hindgut appears to determine whether net degradation and net synthesis of amino acids will take place. The lower digestibility based on fecal in the present study suggested that some fermentable carbohydrates reached the large intestines, though that the quantities were too low to cause significance differences between calculations. On the other hand, the higher ileal value could be due also to contamination of fecal with scurf and feathers. In the current study, the antibiotic treatment group followed by the prebiotic treatment group had the highest ileal protein content compared to all the treatment groups while mixture treatment group had the least ileal protein content compared to the control and other treatment groups. Also, the antibiotic treatment group followed by the prebiotic treatment group had the highest cecal protein content compared to all the treatment groups while mixture had the least cecal content compared to the control group and other treatment groups.

\section{Conclusion}

As the poultry industries are now facing challenges of maintaining production performance of birds due to restriction in the use of antibiotics growth promoters and increased cost of quality feeds and due to the ban on the use of Antibiotic Growth Promoters (AGPs). The withdrawal of AGPs from poultry feed requires the industry to look for various alternatives to maintain or improve the health and performance of birds. The current study was focused on the use of alternative feed additives such as probiotics, essential oil, enzymes, organic acid, mixtures and prebiotics to enhance gut health and reduce losses due to enteric infections. Among the various additives used in this experiment, prebiotic, had significant effect on broilers growth performance, intestinal morphology and gut microbial composition. As such, it can be used as alternative to antibiotic growth promoter.

\section{Acknowledgment}

The authors are grateful to dr. A.K. Lawal, Dr. Frank Orji and other staff of federal Institute of Industrial Research, Oshodi, Lagos for their supports.

\section{Author's Contributions}

Sunday Egba Omogo: Conceived and designed the experiments, performed the experiment and processed the data, analyzed the data and wrote the manuscript. 
Emeka Henry Oparaji: Supervised the research, analyzed data, interpreted the data and revised the manuscript.

Franklin Uzodinma Edeji: Co-supervised the research and revised the manuscript.

\section{Ethics}

This article is original and contains unpublished material. The corresponding author confirms that all of the other authors have read and approved the manuscript and no ethical issues involved.

\section{References}

Aarestrup, F. M. (1999). Association between the consumption of antimicrobial agents in animal husbandry and the occurrence of resistant bacteria among food animals. International Journal of Antimicrobial Agents, 12(4), 279-285. doi.org/10.1016/S0924-8579(99)90059-6

Association of Official Analytical Chemists. (1990). official methods of Analysis. Association of official analytical chemistry, Washington, Dc, USA.

Apajalahti, J., Kettunen, A., \& Graham, H. (2004). Characteristics of the gastrointestinal microbial communities, with special reference to the chicken. World's Poultry Science Journal, 60(2), 223-232. doi.org/10.1079/WPS200415

Apajalahti, J. H., Kettunen, A., Bedford, M. R., \& Holben, W. E. (2001). Percent $\mathrm{G}+\mathrm{C}$ profiling accurately reveals diet-related differences in the gastrointestinal microbial community of broiler chickens. Applied and Environmental Microbiology, 67(12), 5656-5667. doi.org/10.1128/AEM.67.12.5656-5667.2001

Apajalahti, J. H., Kettunen, H., Kettunen, A., Holben, W. E., Nurminen, P. H., Rautonen, N., \& Mutanen, M. (2002). Culture-independent microbial community analysis reveals that inulin in the diet primarily affects previously unknown bacteria in the mouse cecum. Applied and Environmental Microbiology, 68(10), 4986-4995.

doi.org/10.1128/AEM.68.10.4986-4995.2002

Amit-Romach, E., Sklan, D., \& Uni, Z. (2004). Microflora ecology of the chicken intestine using $16 \mathrm{~S}$ ribosomal DNA primers. Poultry Science, 83(7), 1093-1098. doi.org/10.1093/ps/83.7.1093

Angel, R., Dalloul, R. A., \& Doerr, J. (2005). Performance of broiler chickens fed diets supplemented with a direct-fed microbial. Poultry Science, 84(8), 1222-1231. doi.org/10.1093/ps/84.8.1222

Batal, A. B., \& Parsons, C. M. (2002). Effects of age on nutrient digestibility in chicks fed different diets. Poultry Science, 81(3), 400-407. doi.org/10.1093/ps/81.3.400
Baurhoo, B., Phillip, L., \& Ruiz-Feria, C. A. (2007). Effects of purified lignin and mannan oligosaccharides on intestinal integrity and microbial populations in the ceca and litter of broiler chickens. Poultry Science, 86(6), 1070-1078. doi.org/10.1093/ps/86.6.1070

Biggs, P., \& Parsons, C. M. (2007). The effects of several oligosaccharides on true amino acid digestibility and true metabolizable energy in cecectomized and conventional roosters. Poultry Science, 86(6), 1161-1165. doi.org/10.1093/ps/86.6.1161

Burkholder, K. M., Applegagte, T. J., \& Patterson, J. A. (2005, January). Performance and intestinal characteristics of broilers fell salinomycin, fructooligosaccharides, probiotics and synbiotics. In Poultry Science (Vol. 84, pp. 108-108). 1111 N Dunlap Ave, Savoy, IL 61874-9604 USA: Poultry Science Assoc Inc.

Cave, N. A. G. (1982). Effect of dietary short-and medium-chain fatty acids on feed intake by chicks. Poultry Science, 61(6), 1147-1153. doi.org/10.3382/ps.0611147

Charles, O. W., \& Duke, S. (1978, January). Response of laying hens to dietary fermentation products and probiotic-antibiotic combinations. In Poultry Science (Vol. 57, No. 4, pp. 1125-1125). 1111 North Dunlap Ave, Savoy, IL 61874: Poultry Science Assoc Inc.

Cromwell, G. L. (2002). Why and how antibiotics are used in swine production. Animal Biotechnology, 13(1), 7-27. doi.org/10.1081/ABIO-120005767

Dibner, J. J., \& Buttin, P. (2002). Use of organic acids as a model to study the impact of gut microflora on nutrition and metabolism. Journal of Applied Poultry Research, 11(4), 453-463. doi.org/10.1093/japr/11.4.453

Donoghue, D. J. (2003). Antibiotic residues in poultry tissues and eggs: Human health concerns? Poultry Science, 82(4), 618-621. doi.org/10.1093/ps/82.4.618

Ezeonu, I. M., Akobueze, E. U., \& Chah, K. F. (2012). Prebiotic effects of Vernonia amygdalina and Ocimum gratissimum aqueous leaf extracts in rabbit (Oryctolagus cuniculus). African Journal of Biotechnology, 11(10), 2537-2547. doi.org/10.5897/AJB11.2251

Fenton, T. W., \& Fenton, M. (1979). An improved procedure for the determination of chromic oxide in feed and feces. Canadian Journal of Animal Science, 59(3), 631-634. doi.org/10.4141/cjas79-081

Gabriel, I., Lessire, M., Mallet, S., \& Guillot, J. F. (2006). Microflora of the digestive tract: Critical factors and consequences for poultry. World's Poultry Science Journal, 62(3), 499-511. doi.org/10.1017/S0043933906001115 
Gao, J., Zhang, H. J., Yu, S. H., Wu, S. G., Yoon, I., Quigley, J., ... \& Qi, G. H. (2008). Effects of yeast culture in broiler diets on performance and immunomodulatory functions. Poultry Science, 87(7), 1377-1384. doi.org/10.3382/ps.2007-00418

Gong, J., Forster, R. J., Yu, H., Chambers, J. R., Sabour, P. M., Wheatcroft, R., \& Chen, S. (2002a). Diversity and phylogenetic analysis of bacteria in the mucosa of chicken ceca and comparison with bacteria in the cecal lumen. FEMS Microbiology Letters, 208(1), 1-7. doi.org/10.1111/j.1574-6968.2002.tb11051.x

Gong, J., Forster, R. J., Yu, H., Chambers, J. R., Wheatcroft, R., Sabour, P. M., \& Chen, S. (2002b). Molecular analysis of bacterial populations in the ileum of broiler chickens and comparison with bacteria in the cecum. FEMS Microbiology Ecology, 41(3), 171-179. doi.org/10.1111/j.1574-6941.2002.tb00978.x

Hernandez, F., Garcia, V., Madrid, J., Orengo, J., Catala, P., \& Megias, M. D. (2006). Effect of formic acid on performance, digestibility, intestinal histomorphology and plasma metabolite levels of broiler chickens. British Poultry Science, 47(1), 50-56. doi.org/10.1080/00071660500475574

Houshmand, M., Azhar, K., Zulkifli, I., Bejo, M. H., \& Kamyab, A. (2012). Effects of non-antibiotic feed additives on performance, immunity and intestinal morphology of broilers fed different levels of protein. South African Journal of Animal Science, 42(1), 23-32. doi.org/10.4314/sajas.v42i1.3

Isabel, B. A. S. Y., \& Santos, Y. (2009). Effects of dietary organic acids and essential oils on growth performance and carcass characteristics of broiler chickens. Journal of Applied Poultry Research, 18(3), 472-476. doi.org/10.3382/japr.2008-00096

Jeurissen, S. H., Lewis, F., van der Klis, J. D., Mroz, Z., Rebel, J. M., \& Ter Huurne, A. A. (2002). Parameters and techniques to determine intestinal health of poultry as constituted by immunity, integrity and functionality. Current Issues in Intestinal Microbiology, 3(1), 1-14.

Kadim, I., Mahgoub, O., Al-Maqbaly, R., Annamalai, K., \& Al-Ajmi, D. (2002). Effect of age on fatty acid composition on hump and abdomen depot fats of Arabian camel (Camelus dromedaries). Meat Science, 62, 245-251. doi.org/10.1016/S0309-1740(01)00254-6

Kadim, I. T., \& Moughan, P. J. (1997). Ileal amino acid digestibility assay for the growing meat chickeneffect of the imposition of a fasting period and the nature of the test diet. British Poultry Science, 38(3), 285-290.

doi.org/10.1080/00071669708417988
Lee, K., Lillehoj, H. S., \& Siragusa, G. R. (2010). Direct-fed microbials and their impact on the intestinal microflora and immune system of chickens. The Journal of Poultry Science, 1001160039-1001160039.

Montagne, L., Pluske, J. R., \& Hampson, D. J. (2003). A review of interactions between dietary fibre and the intestinal mucosa and their consequences on digestive health in young non-ruminant animals. Animal Feed Science and Technology, 108(1-4), 95-117. doi.org/10.1016/S0377-8401(03)00163-9

Naji, S., Al-kassie, G., Al-Hadithi, M., Al-Hillali, A., \& Jameel, Y. (2009). Poultry health management. Iraqi poultry producer association. Brochure No (27). (Arabic).

NRC. (1994). Nutrient Requirements of Poultry. National Academy Press, Washington, D.C., USA.

Oyibo, K., Johson, S. A., \& Jerikins, S. V. (2018). Presence of antibiotics resistant Escherichia coli in waste water treatment plant effluents utilized as water reuse for irrigation. African Journal of Biotechnology, 18, 115-245.

Papadopoulos, M. C., (1998). Estimation of amino acid digestibility and availability in feed stuffs for poultry,www.atlas.sct.embrapa.br/pub/pub/.nsf/a441

Parsons, J. W. (1984). Green manuring. SAGE Journal, 13, 20-23. doi.org/10.1177/003072708401300103

Patterson, J. A., \& Burkholder, K. M. (2003). Application of prebiotics and probiotics in poultry production. Poultry Science, 82(4), 627-631. doi.org/10.1093/ps/82.4.627

Samarasinghe, K., Wenk, C., Silva, K. F. S. T., \& Gunasekera, J. M. D. M. (2003). Turmeric (Curcuma longa) root powder and mannanoligosaccharides as alternatives to antibiotics in broiler chicken diets. Asian-Australasian Journal of Animal Sciences, 16(10), 1495-1500. doi.org/10.5713/ajas.2003.1495

Timmerman, H. M., Veldman, A., Van den Elsen, E., Rombouts, F. M., \& Beynen, A. C. (2006). Mortality and growth performance of broilers given drinking water supplemented with chicken-specific probiotics. Poultry Science, 85(8), 1383-1388. doi.org/10.1093/ps/85.8.1383

Torres-Rodriguez, A., Sartor, C., Higgins, S. E., Wolfenden, A. D., Bielke, L. R., Pixley, C. M., ... \& Hargis, B. M. (2005). Effect of Aspergillus meal prebiotic (fermacto) on performance of broiler chickens in the starter phase and fed low protein diets. Journal of Applied Poultry Research, 14(4), 665-669. doi.org/10.1093/japr/14.4.665

Van der Fels-kerx, H., Sorensen, A., Jalving, A., \& Huirne, R. (2011). An economic model to calculate farm-specific losses due to bovine respiratorydisease in diary heifers. Previews in Vertinary Medicine, 51, 75-94. doi.org/10.1016/s0167-5877(01)00208-2 
Willis, W. L., \& Reid, L. (2008). Investigating the effects of dietary probiotic feeding regimens on broiler chicken production and Campylobacter jejuni presence. Poultry Science, 87(4), 606-611. doi.org/10.3382/ps.2006-00458

Willis, W. L., Goktepe, I., Isikhuemhen, O. S., Reed, M., King, K., \& Murray, C. (2008). The effect of mushroom and pokeweed extract on Salmonella, egg production and weight loss in molting hens. Poultry Science, 87(12), 2451-2457. doi.org/10.3382/ps.2008-00004

Willis, W. L., Isikhuemhen, O. S., Allen, J. W., Byers, A., King, K., \& Thomas, C. (2009a). Utilizing fungus myceliated grain for molt induction and performance in commercial laying hens. Poultry Science, 88(10), 2026-2032. doi.org/10.3382/ps.2009-00120

Willis, W. L., King, K., Iskhuemhen, O. S., \& Ibrahim, S. A. (2009b). Administration of mushroom extract to broiler chickens for bifidobacteria enhancement and Salmonella reduction. Journal of Applied Poultry Research, 18(4), 658-664.

doi.org/10.3382/japr.2008-00101
Willis, W. L., Isikhuemhen, O. S., Minor, R. C., Hurley, S., \& Ohimain, E. I. (2010). Comparing the feeding of fungus myceliated grain with other anticoccidial control measures on oocyst excretion of Eimeria challenged broilers. International Journal of Poultry Science, 9(7), 648-651. doi.org/10.3923/ijps.2010.648.651

Xu, Z. R., Wang, M. Q., Mao, H. X., Zhan, X. A., \& $\mathrm{Hu}, \mathrm{C}$. H. (2003). Effects of L-carnitine on growth performance, carcass composition and metabolism of lipids in male broilers. Poultry Science, 82(3), 408-413. doi.org/10.1093/ps/82.3.408

Yang, Y., Iji, P. A., \& Choct, M. (2009). Dietary modulation of gut microflora in broiler chickens: A review of the role of six kinds of alternatives to infeed antibiotics. World's Poultry Science Journal, 65(1), 97-114. doi.org/10.1017/S0043933909000087

Yegani, M., \& Korver, D. R. (2008). Factors affecting intestinal health in poultry. Poultry Science, 87(10), 2052-2063. doi.org/10.3382/ps.2008-00091 